THE JOURNAL OF TRANSPORT AND LAND USE http://jtlu.org

VOL. 11 NO. 1 [2018] pp. 367-385

\title{
Mobility tools and use: Accessibility's role in Switzerland
}

\author{
Allister Loder \\ Institute for Transport Planning and Systems, ETH Zurich \\ Kay W. Axhausen \\ Institute for Transport Planning and Systems, ETH Zurich
}

\begin{abstract}
In much of Switzerland, public transport offers high levels of accessibility to workplaces and other places that make season tickets legitimate substitutes for a car. These similar patterns of accessibility provided by both modes result in high levels of correlation between the accessibility measures of both modes. This correlation almost always precludes a travel behavior analysis with several accessibility measures and cannot provide any insights into the effects of the differences in accessibility levels by both modes. We propose a principal component analysis of the accessibility measures to extract as much information as possible. We interpret the principal components obtained as: general accessibility, comparatively better accessibility by public transport and comparatively better job accessibility.

The new accessibility variables are used in a model of car and season ticket ownership and the number of car, public transport and non-motorized trips using data from the 2010 Swiss transportation microcensus. These outcomes are jointly estimated with a probit-based model for mixed types of outcomes because we anticipated simultaneous choices and that choices are dependent on each other. We found that greater levels of general accessibility, comparatively better accessibility by public transport and comparatively better job accessibility increased the probability of season ticket ownership, while the probability of car ownership decreased. We realize that ownership and use must be jointly modeled to consistently estimate the structural effects of mobility tool ownership on use.
\end{abstract}

Article History:

Received: October

31, 2016

Revised Paper Received:

March 28, 2017

Accepted: January 22,

2018

Available online: April

12,2018

\section{Introduction}

Mobility tools available to an individual, e.g., car or public transport season ticket, are central to his or her activity pattern and mode choice (Eluru et al. 2010; Guo et al. 2007; Le Vine et al. 2013; Paleti et al. 2013). In much of Switzerland, quality public transport makes season tickets legitimate substitutes for a car.

Copyright 2018 Allister Loder, Kay W. Axhausen.

doi: $10.5198 /$ jtlu.2018.1054

ISSN: 1938-7849 | Licensed under the Creative Commons Attribution - NonCommercial License 4.0.

The Journal of Transport and Land Use is the official journal of the World Society for Transport and Land Use (WSTLUR) and is published and sponsored by the University of Minnesota Center for Transportation Studies. This paper is also published with additional sponsorship from WSTLUR. 
With average annual costs of around CHF 10'000 for a car and CHF 4'000 for a nation wide season ticket, public transport offers within many cities and between the large cities similar, but more reliable travel times, e.g., from Bürkliplatz at Lake Zurich to the airport in around $22 \mathrm{~min}$, while, depending on traffic, car travel times range from 16-26 min, both according to Google's journey planner.

The spatial distribution of these areas can be described by concepts of the built environment (Ewing and Cervero 2010): destination accessibility, using the private or public mode, and distance to and quality of - public transport. The close competition of modes in Switzerland leads to similar patterns of accessibility provided by public transport and cars and results in a strong correlation of these measures, which imposes the risk of multicollinearity. Although the choices of mobility tool ownership and use are related, the competing nature of private and public modes - measured by accessibility - in analyzing multi modal travel choices has not been prominently addressed in literature.

So far, most mobility tool ownership studies focused on car ownership (Anowar et al. 2014; de Jong et al. 2004), but some also included other mobility tools (e.g., Scott and Axhausen 2006; Yamamoto 2009); the same holds for ownership and use with a focus on cars (e.g., Bhat and Sen 2006; Tanner and Bolduc 2014) and less on cars and public transport (e.g., Simma and Axhausen 2001). However, Bhat and colleagues' recently proposed methodology to jointly model mixed types of outcomes offers as a flexible framework to analyze multi modal travel choices of mobility tool ownership and use (Bhat 2015; Bhat et al. 2014; Paleti et al. 2013). Regarding the competition in the generalized cost of travel of modes, the comparison of accessibility by both modes has rarely been attempted; most studies focused either on accessibility by car or public transport (Ewing and Cervero 2010) and only a few combined both modes (e.g., Jäggi et al. 2012; Kuzmyak et al. 2006; Scott and Axhausen 2006; Shen 2000).

In this paper, we contribute with the proposal of a principal component analysis of correlating accessibility measures to extract as much information as possible for the analysis of mode competition in understanding travel behavior. We obtain a Hansen (1959)-based measure of accessibility, based on travel times from the Swiss nation-wide transport model for the private and public mode. We use the idea of Shen's 2000 general accessibility index and obtain values from a principal component analysis. From this analysis, we derive, in total, three new accessibility variables for each Swiss municipality: general accessibility, comparatively better accessibility by public transport and comparatively better job accessibility. These variables are used in a joint statistical model of mobility tools ownership and number of trips by car, public transport and non-motorized modes (Bhat 2015; Bhat et al. 2014). In addition to the new accessibility variables, we add two more measures of the built environment: quality of public transport at the household location and a spatial typology definition of urban center, agglomeration and countryside. In our model, we also control for socio-demographic factors such as income, age and gender.

This paper is organized as follows. Section 2 reviews the relevant literature. Section 3 presents the data for this analysis. In Section 4, we present the statistical model, followed by estimation results in Section 5. The paper concludes with a discussion and conclusion.

\section{Background}

This section provides a literature overview for each of the two related fields; the volume of existing literature necessitates just a sketch. Section 2.1 addresses the relationship between the built environment and travel behavior with a focus on destination accessibility and distance to public transport, because both are relevant for this analysis. In the following, we treat destination accessibility and accessibility as synonyms. Thereafter, Section 2.2 summarizes methodologies to model travel behavior choices in terms of ownership and use. 


\subsection{Influence of the built environment}

The built environment or land-use of an area is frequently found to be a strong predictor of travel behavior. Ewing and Cervero $(2001,2010,2017)$ provided extensive and comprehensive overviews on the relationship between the built environment and travel behavior. Ewing and Cervero (2010) follow the three $D s$ categorization of built environment measures, as introduced by Cervero and Kockelman (1997): density, diversity and design, but also include two further $D$ variables: destination accessibility and distance to - and quality of - public transport. In the following, we focus on the latter measures as they describe the interaction of the transport and land-use system relevant for this analysis.

Accessibility is a generalization of the population-over-distance relationship (Hansen 1959) and a measure of generalized cost of travel (Weis and Axhausen 2009). Metz (2008) argued that accessibility corresponds to the long-term benefits of transport investments. For a region with $N$ locations, the Hansen (1959) definition of accessibility at location $i$ links all opportunities $O_{j}$ at other places $j$ to the travel cost (time) $c_{i j}$ of reaching these opportunities. Typically, more distant opportunities are less favored; weighting opportunities by a function of travel costs $f\left(c_{i j}\right)$ considers this. A conventional formulation of accessibility is $A_{i}=\sum_{j=1}^{N} O_{j} f\left(c_{i j}\right)$. Among others, the function $f\left(c_{i j}\right)$ can be the inverse of travel costs or an exponential function with a negative parameter. Depending on analysis, various measures for opportunities can be used, e.g., number of employed (Hansen 1959), population (Killer et al. 2013) and housing and retail (Crozet et al. 2012). Besides Hansen's definition of accessibility, other models exist, e.g., based on logit models' systematic utilities (Ben Akiva and Lerman 1985), individuals' travel costs to their activities (Le Vine et al. 2013), or the cumulative opportunities measure around a location (Handy and Niemeier 1997). For a general discussion on accessibility perspectives, we refer the interested reader to the review by Geurs and van Wee (2004).

Ewing and Cervero (2010) reported that in general better accessibility reduces car usage, while less distance to the public transport stop favors walking and public transport use. Houston et al. (2014) analyzed the effect of the age of rail corridors and found less car use for older rail corridors than for newer. The effect of distance to public transport stops also is found for car ownership (e.g., Bento et al. 2005; Zegras 2010). These findings suggest the hypotheses that car ownership and use is reduced with better accessibility and better local access to public transport, while the opposite holds for public transport and walking.

\subsection{Modeling travel behavior - mobility tool ownership and use}

Modeling mobility tool ownership almost always means car ownership modeling (Le Vine et al. 2013). Car ownership models range from aggregate level models to disaggregate household and individual level models, for which different methodologies exist to describe the decision-making process. In lieu of a comprehensive overview here, we refer to literature reviews by de Jong et al. (2004), de Jong and Kitamura (2009) and Anowar et al. (2014).

From a methodological perspective, Anowar et al. (2014) divided ownership models into four groups. First, exogenous static models consider ownership choices independently of other choices. These models deploy standard discrete choice models, e.g., logit, probit or the multinomial logit (MNL) (e.g., Karlaftis and Golias 2002; Potoglou and Kanaroglou 2008; Vovsha and Petersen 2009; Zegras 2010). The second group describes endogenous static models capturing other choices as well (e.g., Bhat and Guo 2007; Cao et al. 2007). The last two groups are the dynamic counterparts of the first two static model types. In particular, the third group describes exogenous dynamic models and the fourth group endogenous dynamic models, using panel data (e.g., Dargay 2002; Nolan 2010).

Joint modeling of multiple related outcomes, e.g., car ownership and use, is motivated by potential common, underlying, unobserved factors in the decision-making process that simultaneously affect outcomes. Ignoring jointness in choices can lead to inefficient estimates of effects and inconsistent estimates of structural effects (Bhat et al. 2016). 


\begin{tabular}{|c|c|c|c|c|c|c|c|}
\hline \multirow{2}{*}{\multicolumn{2}{|c|}{ Mobility tool }} & \multicolumn{4}{|c|}{ Season ticket } & \multirow{2}{*}{\multicolumn{2}{|c|}{ Total }} \\
\hline & & \multicolumn{2}{|c|}{ No } & \multicolumn{2}{|c|}{ Yes } & & \\
\hline & & $\mathrm{N}$ & $\%$ & $\mathrm{~N}$ & $\%$ & $\mathrm{~N}$ & $\%$ \\
\hline \multirow{2}{*}{ Car } & No & 9396 & 18.10 & 8309 & 15.83 & $17 ' 805$ & 33.93 \\
\hline & Yes & $29 ’ 364$ & 55.96 & $5 ’ 307$ & 10.11 & $34{ }^{\prime} 671$ & 66.07 \\
\hline \multicolumn{2}{|c|}{ Total } & $38^{\prime} 860$ & 74.05 & $13^{\prime} 616$ & 25.95 & $52 ' 476$ & 100 \\
\hline
\end{tabular}

Table 1: Jointness in mobility tool ownership, illustrated by the cross tabulation of car and season ticket ownership.

Jointness can be established in several ways. First, multivariate probit-based models consider common underlying factors in multiple outcomes via error term correlation (e.g., Andrés and Gélvez 2014; Scott and Axhausen 2006; Yamamoto 2009). If two outcomes exhibit a positive correlation, common underlying factors affect both outcomes in the same direction, i.e. they are complementary goods, while a negative correlation indicates substitute goods. Building on the multivariate probit, Bhat and colleagues extended the multivariate probit to model mixed types of dependent variables, e.g., nominal, ordinal, count and continuous outcomes, e.g., location, car ownership, number of trips and trip distance (Bhat 2015; Bhat et al. 2014). This modeling approach has also proved suitable for accommodating spatial or social interactions (Bhat et al. 2016). Second, copula based models define linking functions between the error terms of outcomes other than the normal distribution, i.e., Gaussian copula (e.g., Spissu et al. 2009). Third, in the multiple discrete-continuous extreme value (MDCEV) model (Bhat 2005) the consumption of both, discrete goods, e.g., cars, and continuous goods, e.g., annual mileage, enters the same utility function that is maximized (e.g., Bhat and Sen 2006; Jäggi et al. 2012; Tanner and Bolduc 2014). Last, structural equation modeling with car and season ticket ownership and their use as dependent variables offers another way to incorporate jointness (e.g., Simma and Axhausen 2001).

\section{Data}

\subsection{Socioeconomic data}

Data on mobility tool ownership, number of trips and accompanying socio-demographic information is provided by the Swiss national transportation microcensus for the year 2010. The transportation microcensus is a large-scale survey carried out every five years with approximately $1 \%$ of the Swiss population. In 2010, 59'771 households and - within these households, 62'868 individuals - were interviewed about their travel behavior (Swiss Federal Office of Statistics (BFS) and Swiss Federal Office of Spatial Development (ARE) 2012). We exclude anyone who can only move with outside support, all cases where we cannot impute the income and all cases younger than 18 from the sample. When two persons of a household reported on their travel behavior in the census, the second observation was in most cases a child. The final sample has 52'476 complete observations.

This analysis models individuals' decision making. For each individual in the data set, we extract five dependent variables of interest, car and season ticket ownership and the number of car, public transport and non-motorized trips as follows: car ownership is defined as having a car exclusively available. All individuals without driver's license are coded as having no car available. Season ticket ownership is defined as having any kind of season ticket subscription offering unlimited use of public transport, on either a regional or national scale. The number of trips is taken from the microcensus' travel diary, encompassing a single day. In each of the three trip variables, we pool the count outcomes of 1 and 2 trips into a single outcome and all outcomes larger than 11 to the outcome of 11 . We did the first because just one trip was rarely observed and the latter because we wanted to avoid long tails in the distribution. Table 4 shows descriptive statistics of the five dependent variables in this analysis. 


\begin{tabular}{lrrrrrr}
\hline Number & \multicolumn{2}{c}{ Car } & \multicolumn{2}{c}{ Public transport } & \multicolumn{2}{c}{ Non-motorized } \\
\hline & \multicolumn{1}{c}{$\mathrm{N}$} & \multicolumn{1}{c}{$\%$} & \multicolumn{1}{c}{$\mathrm{N}$} & \multicolumn{1}{c}{$\%$} & \multicolumn{1}{c}{$\mathrm{N}$} & \multicolumn{1}{c}{$\%$} \\
\hline 0 & $23^{\prime} 833$ & 45.40 & $42^{\prime} 704$ & 81.40 & $26^{\prime} 700$ & 50.90 \\
1 to 2 & $13^{\prime} 758$ & 26.20 & $7^{\prime} 719$ & 14.70 & $16^{\prime} 811$ & 32.00 \\
3 & $4^{\prime} 134$ & 7.90 & $1^{\prime} 194$ & 2.30 & $3^{\prime} 628$ & 6.90 \\
4 & $5^{\prime} 208$ & 9.90 & 661 & 1.30 & $2^{\prime} 915$ & 5.60 \\
5 & $2^{\prime} 333$ & 4.40 & 124 & 0.20 & $1^{\prime} 114$ & 2.10 \\
6 & $1^{\prime} 628$ & 3.10 & 58 & 0.10 & 759 & 1.40 \\
7 & 724 & 1.40 & 12 & 0.00 & 278 & 0.50 \\
8 & 414 & 0.80 & 0 & 0.00 & 148 & 0.30 \\
9 & 223 & 0.40 & 3 & 0.00 & 55 & 0.10 \\
10 & 119 & 0.20 & 1 & 0.00 & 35 & 0.10 \\
$>10$ & 102 & 0.20 & 0 & 0.00 & 33 & 0.10 \\
\hline
\end{tabular}

Table 2: Distribution of number of trips reported in travel diary (one day). Around $50 \%$ of the sample reported a car trip. Contrary, $20 \%$ of the people surveyed took at least one trip by public transport.

\begin{tabular}{lccrr}
\hline \multirow{2}{*}{ Mobility tool } & & \multicolumn{4}{c}{ Number of trips } \\
\hline \multirow{2}{*}{ Car } & No & 0.489 & 0.477 & 1.103 \\
& Yes & 1.660 & 0.130 & 0.727 \\
\hline \multirow{2}{*}{ Season ticket } & No & 1.489 & 0.088 & 0.831 \\
& Yes & 0.616 & 0.701 & 0.922 \\
\hline \multirow{2}{*}{ Total } & & 1.262 & 0.247 & 0.855 \\
\hline
\end{tabular}

Table 3: Average number of car public transport and non-motorized trips conditional on mobility tool ownership. The ownership of a car or a season ticket corresponds to an increase in car or public transport trips, respectively. Distribution of the five dependent variables; statistics on the five dependent variables in the analysis of mobility tool ownership and use. Data from the Swiss transportation microcensus 2010.

Table 1 shows that $55.96 \%$ of all observations only have a car, $18.1 \%$ have neither a car nor a season ticket, $15.83 \%$ have only a season ticket and $10.11 \%$ have both mobility tools available. Table 2 shows the univariate distributions of the number of trips by car, public transport and non-motorized modes. The total share of immobile persons in the dataset is $10.6 \%$. However, we cannot ignore the potential influence of soft-refusal (not reporting of shorter trips), especially for the non-motorized trips (Madre et al. 2007). The accumulation of zero trips is highest for public transport trips and lowest for car trips, which also shows the longest tail. In Table 3 we present the average number of trips distinguished by mobility tool ownership. Intuitively, car ownership increases the number of car trips and reduces the number of public transport and non-motorized trips, while the opposite occurs for season ticket ownership. For season ticket ownership, we observe a slight increase in the number of non-motorized trips.

As explanatory variables, we select from the microcensus gender, age (grouped by age categories), employment status, university degree and monthly gross household income ${ }^{1}$. We describe the residential location of each observation by three spatial variables: first, a generalization of a Hansen (1959)based accessibility measure that we introduce in the next section; second, a spatial typology definition from the Swiss Federal Office of Spatial Development (ARE) et al. (2011) to differentiate between urban, agglomeration and non-urban environment and, third, the quality of public transport, the lat-

\footnotetext{
${ }^{1}$ We recode the stated gross monthly household income classes into a continuous scale by assigning the midpoint value of each class to the household. As $24 \%$ of all households did not report on their income, we impute the income with an ordered logit model. For each household that did not report income, we assign the sum of the product of probability of belonging to a class with the midpoint income class value. Results available on request.
} 


\begin{tabular}{|c|c|c|c|c|}
\hline Categorical variables & \multicolumn{4}{|l|}{ Share } \\
\hline Person is male & \multicolumn{4}{|l|}{$45.53 \%$} \\
\hline \multicolumn{5}{|l|}{ Age categories } \\
\hline$>70$ & \multicolumn{4}{|l|}{$16.96 \%$} \\
\hline $61-70$ & \multicolumn{4}{|l|}{$17.39 \%$} \\
\hline $51-60$ & \multicolumn{4}{|l|}{$17.59 \%$} \\
\hline $41-50$ & \multicolumn{4}{|l|}{$19.09 \%$} \\
\hline $31-40$ & \multicolumn{4}{|l|}{$15.11 \%$} \\
\hline$<31$ & \multicolumn{4}{|l|}{$13.86 \%$} \\
\hline Employed & \multicolumn{4}{|l|}{$62.26 \%$} \\
\hline University degree & \multicolumn{4}{|c|}{$16.32 \%$} \\
\hline \multicolumn{5}{|c|}{ Quality of public transport at household location } \\
\hline Level A: very good & \multicolumn{4}{|c|}{$12.60 \%$} \\
\hline Level B: good & \multicolumn{4}{|l|}{$16.11 \%$} \\
\hline Level C: moderate & \multicolumn{4}{|l|}{$20.85 \%$} \\
\hline Level D: low & \multicolumn{4}{|c|}{$26.70 \%$} \\
\hline Level E: very low & \\
\hline \multicolumn{5}{|c|}{ Spatial typology at household location } \\
\hline City & \multicolumn{4}{|c|}{$32.50 \%$} \\
\hline Agglomeration & \multicolumn{4}{|l|}{$48.45 \%$} \\
\hline Countryside & \multicolumn{4}{|l|}{$19.05 \%$} \\
\hline \multicolumn{5}{|l|}{ Continuous variables } \\
\hline & Mean & SD & Min & Max \\
\hline \multicolumn{5}{|l|}{ General accessibility } \\
\hline & 1.53 & 1.56 & -10.09 & 5.14 \\
\hline \multicolumn{5}{|c|}{ Better accessibility by public transport } \\
\hline & -0.01 & 0.61 & -1.76 & 2.26 \\
\hline \multicolumn{5}{|l|}{ Better job accessibility } \\
\hline & 0.03 & 0.12 & -0.40 & 0.42 \\
\hline \multicolumn{5}{|c|}{ Log of gross monthly household income in CHF } \\
\hline & 8.75 & 0.56 & 7.31 & 9.90 \\
\hline
\end{tabular}

Table 4: Sample summary statistics; the upper part lists categorical variables and the lower part continuous variables.

ter two at the household location. For each location, the Swiss Federal Office of Spatial Development (ARE) (2011) categorized the quality of public transport based on distance to the next station, frequency at this station and available lines on a five-level scale, ranging from from Level $\mathrm{E}$ (worst) to A (best). The Appendix provides a detailed description of the calculation of this scale.

We are aware of potential multicollinearity between the three variables describing residential location, but the correlations do not exceed 0.5 . Table 4 shows sample summary statistics for all variables in the model.

\subsection{Accessibility data}

The Hansen (1959)-based measure of accessibility for Switzerland is based on travel times from the 2010 national macroscopic transport models for car and public transport. In both transport models, zoning follows the municipality boundaries, except for large cities that are further subdivided. Thus, this accessibility measure is not at the household's location, but at the household's municipality level. However, in this study, the measure of quality of public transport (see previous section) captures the effect of the location of the household within a zone / municipality. In total, both models have 2949 zones within Switzerland. We compute for each zone / municipality $i$ its accessibility value $A_{i}$ with Equation 1.

$$
A_{i}=\log \left(\sum_{j=1}^{N} O_{j} \cdot \exp \left(\beta c_{i j}\right)\right) \text {. }
$$


a) Summary statistics

\begin{tabular}{|c|c|c|c|c|}
\hline & Component 1 & Component 2 & Component 3 & Component 4 \\
\hline Eigenvalue & 3.67715 & .310054 & .0112005 & .00159724 \\
\hline Proportion of the Eigenvalue & 0.9193 & 0.0775 & 0.0028 & 0.0004 \\
\hline Cumulative proportion & 0.9193 & 0.9968 & 0.9996 & 1 \\
\hline \multicolumn{5}{|l|}{$N=2949$} \\
\hline \multicolumn{5}{|l|}{ b) Loadings } \\
\hline Population accessibility by car & 0.5019 & -0.4697 & -0.6857 & -0.2394 \\
\hline Job accessibility by car & 0.4969 & -0.5306 & 0.6427 & 0.2419 \\
\hline Population accessibility by public transport & 0.4997 & 0.5099 & -0.2160 & 0.6660 \\
\hline Job accessibility by public transport & 0.5015 & 0.4877 & 0.2647 & -0.6638 \\
\hline \multicolumn{5}{|l|}{ c) Correlations of factors and items } \\
\hline Population accessibility by car & 0.9624 & -0.2615 & -0.0726 & -0.0096 \\
\hline Job accessibility by car & 0.9529 & -0.2955 & 0.0680 & 0.0097 \\
\hline Population accessibility by public transport & 0.9582 & 0.2839 & -0.0229 & 0.0266 \\
\hline Job accessibility by public transport & 0.9616 & 0.2716 & 0.0280 & -0.0265 \\
\hline
\end{tabular}

Table 5: Results of the principal component analysis of the four accessibility variables.

The accessibility $A_{i}$ is a measure of destination accessibility to all other zones $N$ with $O_{j}$ being the number of accessible opportunities in other zones $j . c_{i j}$ are the generalized cost of travel from $i$ to $j$. The distance decay parameter $\beta$ takes into account that more distant destinations are less attractive. For Switzerland, the $\beta$ has been estimated for each mode by Sarlas et al. (2015): $\beta_{C \text { ar }}=-0.261$ and $\beta_{P T}=-0.034$. The generalized cost of travel $c_{i j}$ are equal to the in-vehicle time from $i$ to $j$ for each mode, but for public transport additionally contains access/ egress time, waiting time and transfers. In our analysis, we compute accessibility by both modes to the two different opportunities $O_{j}$ employment and population in each municipality.

Four accessibility measures are thus available, differentiated by opportunities (population and employment) and mode to reach these opportunities (car or public transport): (1) population accessibility by car, (2) job accessibility by car, (3) population accessibility by public transport, and (4) job accessibility by public transport. The four accessibility measures are a highly correlated. Arguably, both modes have a similar coverage because their infrastructures, residential areas and work places overlap. To reduce the probability of multicollinearity, we carry out a principal component analysis following the idea of Jäggi et al. (2012) to reduce the four variables to a meaningful scale for this analysis (Jolliffe 2002). The obtained principal components then recover the essential directions of accessibility in the data. Results of the analysis are presented in Table 5.

The first component explains more than $90 \%$ (as measured in the proportion of the Eigenvalue) of the variation in the data and we interpret it as general accessibility. The second component explains $7.6 \%$ of the variation and describes comparatively better accessibility by public transport and the third component explains $0.3 \%$ of the variation in the data and describes comparatively better job accessibility. The fourth component does not have a meaningful interpretation for this analysis and is thus omitted. A prominent criterion for the selection of the number of principal components is the Eigenvalue criterion. All components with an Eigenvalue of equal or greater than one should be selected. In this analysis, only the first principal component satisfy this criterion. Nevertheless, for three reasons we do not follow this criterion and select the first three principal components. First, we identify for the first three components a meaningful interpretation. Second, if we would consider only the first principal component, which is highly similar to each of the four accessibility measures, the principal component analysis would be pointless because we would ignore the differences in the accessibility measures. Third, we compared different model specifications including either only the first, the first 
two or the first three principal components with a likelihood ratio test and found that using all three components improves the model significantly.

After the estimation of the principal components, we calculate for each zone / municipality the score values for the general accessibility, comparatively better accessibility by public transport and better job accessibility. The calculation multiplies for each zone the four original accessibility values with the loadings from Table 5 for the considered principal component. We then merge the score values of the first three components to the observations in transportation microcensus. We illustrate the spatial distribution of the score values in Figures 1 and 2. Figure 1 shows that the general accessibility is highest in metropolitan regions and the densely populated Swiss plateau, but low in Alpine regions. We have added the Swiss motorway (white lines) and railway (black lines) network to the map. The zones with high levels of general accessibility overlap with motorways and dense railway networks in large parts of the country. Figure 2 shows spatial distribution of the second component, comparatively better accessibility by public transport. Again, we have added the motorway and railway network to the map. The value distribution does not follow the population distribution, as in the case of the general accessibility, but we observe that many municipalities close to the motorway network score low in this accessibility measure. The values do not score highest in centers of metropolitan regions, but in the agglomeration and countryside/ Alpine regions. We can, for example, explain high values in Alpine regions by citing existing railway and limited car networks.

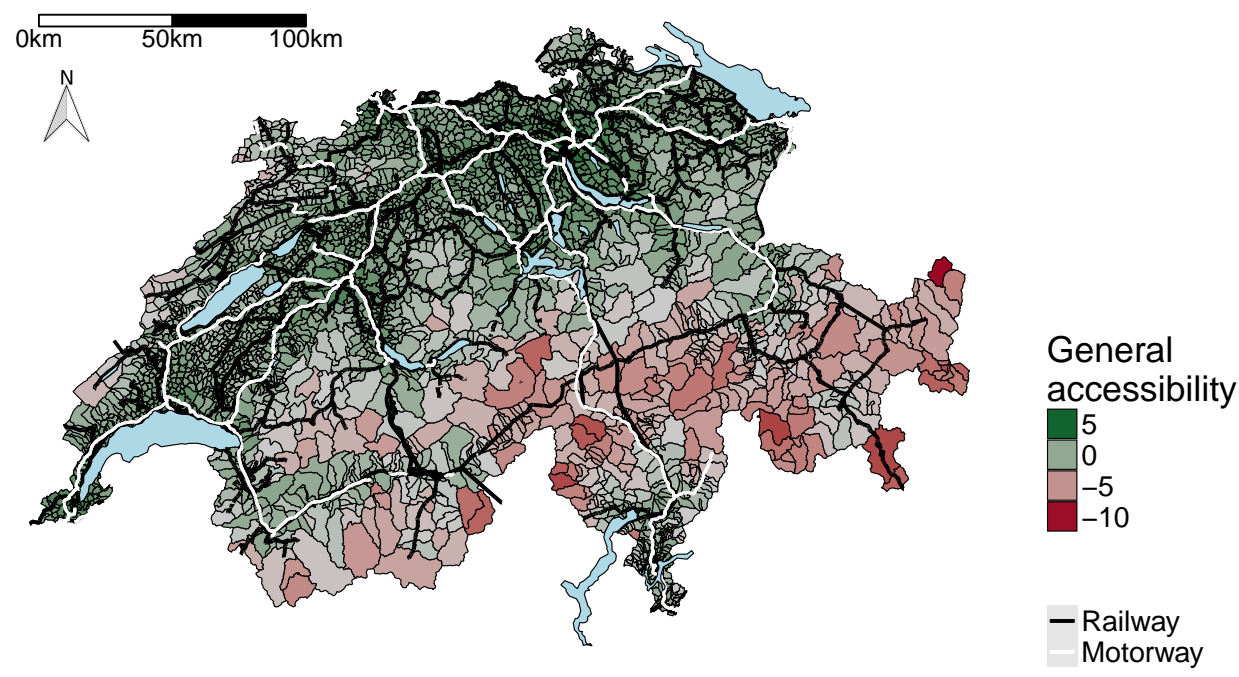

Figure 1: General accessibility levels in Switzerland. The values correspond to the scores calculated from the accessibility values of each municipality and the loading from Table 5 . Higher values mean greater general accessibility. The white lines show the Swiss highway network while the black lines correspond to the main railway network. 

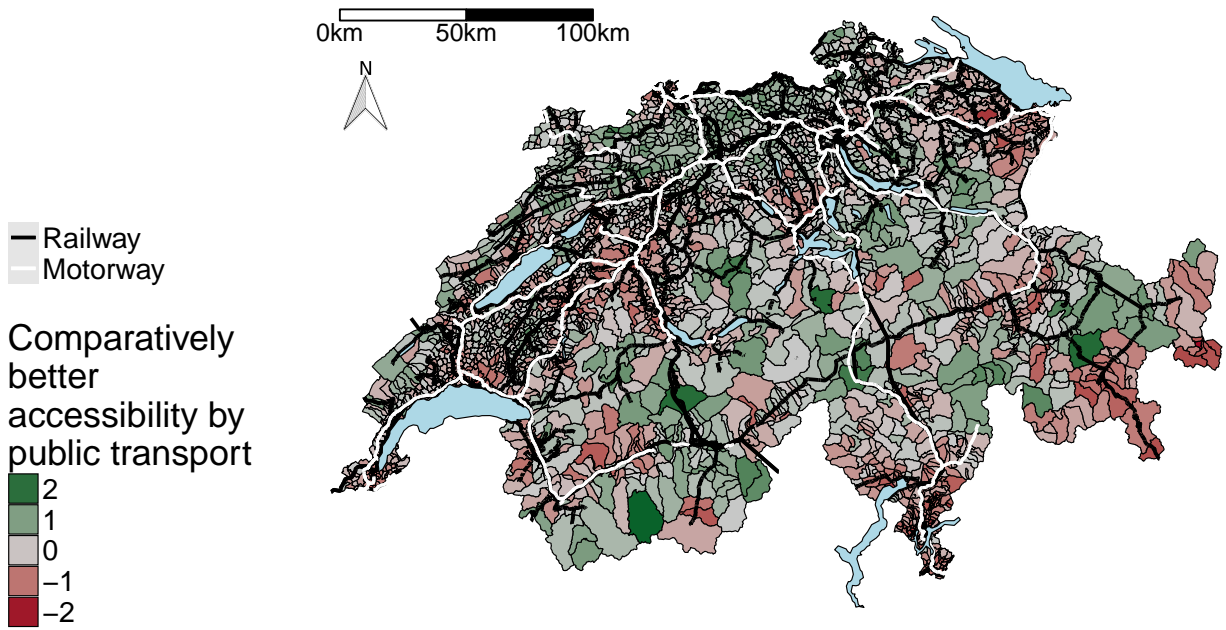

Figure 2: Comparatively better accessibility by public transport. The values correspond to the scores calculated from the accessibility values of each municipality and the loading from Table 5. Higher values mean comparatively better accessibility by public transport. The white lines show the Swiss highway network while the black lines correspond to the main railway network.

\section{Model}

We model mobility tool ownership and use with a multivariate probit-based model for mixed type of outcomes, as introduced by Bhat and his colleagues (Bhat 2015; Bhat et al. 2016; Paleti et al. 2013). For a detailed description, we refer the interested reader especially to Bhat et al. (2014). In this model, relationships between choice outcomes are established by allowing for correlations of error terms and endogenous variables' structural effects. This probit based model is an extension of the traditional multivariate probit, e.g., (e.g., Andrés and Gélvez 2014; Scott and Axhausen 2006; Yamamoto 2009).

For the readers' convenience, we omit in all equations the subscript for number of the outcome equation. The choice of owning a mobility tool is modeled with a binary probit. We define a latent propensity $Y^{*}=\beta x+\varepsilon$, with $\beta$ a vector of coefficients to be estimated, $x$ a vector of exogenous covariates and the normally distributed error term $\varepsilon$. If $Y^{*}>0$, the observed outcome is chosen, i.e. $Y=I\left(Y^{*}>0\right)$. The outcome of number of trips is modeled as a generalized ordered probit (Bhat 2015; Bhat et al. 2014). The generalized ordered probit also has a latent propensity $Y^{*}=\varepsilon$, which is mapped to the observed count outcome $j$ by threshold parameters $\psi_{n}$. For the observed count value $j=n$, the following condition holds $\psi_{n-1}<Y^{*}<\psi_{n}$. The threshold parameters $\psi_{n}$ are determined by the function

$$
\psi_{n}=\Phi^{-1}\left(\frac{(1-c)^{\theta}}{\Gamma(\theta)} \sum_{r=0}^{n}\left(\frac{\Gamma(\theta+r) c^{r}}{r !}\right)\right)+\varphi_{n}
$$


with

$$
c=\frac{\exp (\beta x)}{\exp (\beta x)+\theta}
$$

Dispersion parameter $\theta$ and flexibility parameter $\varphi$ in Equations 2 and 3 allow flexible count distribution modeling. $\Phi$ is the cumulative normal distribution function, $\Gamma$ is the gamma function, $x$ is a vector of exogenous and endogenous covariates and $\beta$ a vector of parameters to be estimated. Error terms of each outcome equation correlate pairwise with $\rho$ and constitute the correlation matrix $P$. For identification, we set $\varphi_{-1}=-\infty, \varphi_{0}=0$ and $\varphi_{n>0}=\varphi$ for each count outcome. The model parameters $\beta, \theta, \varphi$ and $P$ are estimated with maximum likelihood. For each observation the likelihood is defined by

$$
L(\beta, \theta, \phi, P)=\int_{\gamma_{l o w}}^{\gamma_{u p p}} \phi_{5}(\tilde{u} \mid P) d \tilde{u}
$$

The probability is obtained by integrating the five-dimensional normal density distribution $\phi_{5}$ from $\gamma_{\text {low }}$ to $\gamma_{u p p}$, both five-dimensional vectors. For the binary outcome, the lower integration bound is $-\infty$ and the upper integration bound is determined by evaluating the corresponding outcome equation for $Y^{*}$. For the count outcome, the integration domain is determined by individual threshold values $\psi_{n-1}$ and $\psi_{n}$. For the estimation of the model parameters, we use the maximum approximate composite marginal likelihood (MACML) (Bhat et al. 2014; Bhat and Sidharthan 2011) for which Bhat et al. (2010) reported that the MACML approach recovers estimates just as well - but faster - as the simulation approach and that reduction in efficiency by the marginal compared to the simulation approach is "in the range of nonexistent to small". We programmed the routine in Stata (StataCorp. 2015).

\section{Results}

In Table 6, we present, for each of the five outcomes, the univariate estimates; multivariate results are shown in Table 7. Comparing univariate and multivariate estimates, it appears that the effect size differs for most covariates in the second or third significant figure, but the differences seem to be greater for mobility tool's structural effects on the number of trips. Bhat et al. (2014) discussed this issue. Although the univariate estimates display the same tendency as the multivariate estimates, univariate model estimates could be biased. In addition, univariate estimates cannot provide the behavioral insights generated by cross equation correlations presented in Table 8 . We find all count parameters to be significantly different from zero. Therefore, the count models are between a traditional negative binomial and a Poisson count model.

In the following, we focus on multivariate estimates and on the effects of the three spatial variables: accessibility, quality of public transport and spatial typology, as well as the structural effects. The other explanatory variables are as expected and consistent with previous research (Dargay et al. 2007; Ewing and Cervero 2010; Kowald et al. 2017; Simma and Axhausen 2001), except for two effects reported by Simma and Axhausen (2001) with data from 1994. First, the authors reported a negative effect from males on the number of public transport trips, which in our case is insignificant. Second, the authors reported an age effect on public transport trips, directly opposed to our findings.

Each of the three new derived measures of accessibility - general accessibility, comparatively better access by public transport and comparatively better job accessibility - show a negative effect on car ownership. The effects on season ticket ownership are positive for all three variables. We find, for gradually decreasing quality of public transport at household locations, likelihood of car ownership increases and likelihood of season ticket ownership decreases. In the agglomeration, car ownership is greater than in the urban center and the countryside, while car ownership is greater in rural areas than 


\begin{tabular}{|c|c|c|c|c|c|c|c|}
\hline & \multicolumn{4}{|c|}{ Mobility tool ownership } & \multicolumn{3}{|c|}{ Number of trips } \\
\hline & \multicolumn{2}{|c|}{ Car } & \multicolumn{2}{|c|}{ Season ticket } & Car & Public transport & Non-motorized \\
\hline Person is male & $0.461^{* * *}$ & $(0.012)$ & $-0.163^{* * *}$ & $(0.013)$ & $0.119^{* * *}(0.012)$ & a & $-0.083^{\text {*** }}(0.014)$ \\
\hline \multicolumn{8}{|l|}{ Age categories } \\
\hline $61-70$ & $0.324^{* * *}$ & $(0.021)$ & $-0.178^{* * *}$ & $(0.022)$ & $0.212^{* * *}(0.022)$ & $0.222^{* * *}(0.040)$ & $0.196^{\text {**** }}(0.024)$ \\
\hline $51-60$ & $0.124^{* * *}$ & $(0.024)$ & $-0.158^{* * *}$ & $(0.025)$ & $0.293^{* * *}(0.024)$ & $0.331^{* * *}(0.044)$ & $0.141^{\text {**** }}(0.024)$ \\
\hline $41-50$ & $0.106^{* * *}$ & $(0.024)$ & $-0.220^{* * *}$ & $(0.026)$ & $0.381^{* * *}(0.024)$ & $0.294^{* * *}(0.044)$ & $0.190^{* * *}(0.023)$ \\
\hline $31-40$ & 0.010 & $(0.025)$ & $-0.169^{* * *}$ & $(0.026)$ & $0.366^{* * *}(0.025)$ & $0.350^{* * *}(0.045)$ & $0.120^{* * *}(0.025)$ \\
\hline$<31$ & $-0.623^{* * *}$ & $(0.024)$ & $0.385^{* * *}$ & $(0.025)$ & $0.506^{* * *}(0.026)$ & $0.614^{* * *}(0.041)$ & $-0.061^{*} \quad(0.026)$ \\
\hline Employed & $0.322^{* * *}$ & $(0.017)$ & $0.041^{*}$ & $(0.017)$ & $0.310^{* * *}(0.016)$ & $0.163^{* * *}(0.029)$ & a \\
\hline University degree & $-0.050^{* *}$ & $(0.018)$ & $0.156^{* * *}$ & $(0.017)$ & & & \\
\hline \multicolumn{8}{|c|}{ Quality of public transport at household location } \\
\hline Level B: good & $0.165^{* * *}$ & $(0.022)$ & $-0.097^{* * *}$ & $(0.022)$ & & & \\
\hline Level C: moderate & $0.310^{* * *}$ & $(0.024)$ & $-0.245^{* * *}$ & $(0.024)$ & & & \\
\hline Level D: low & $0.415^{* * *}$ & $(0.025)$ & $-0.348^{* * *}$ & $(0.025)$ & & & \\
\hline Level E: very low & $0.554^{* * *}$ & $(0.027)$ & $-0.475^{* * *}$ & $(0.027)$ & & & \\
\hline \multicolumn{8}{|l|}{$\begin{array}{l}\text { Spatial typology at household location } \\
\text { City (base) }\end{array}$} \\
\hline Agglomeration & $0.236^{* * *}$ & $(0.015)$ & $-0.174^{* * *}$ & $(0.015)$ & $0.202^{* * *}(0.014)$ & $-0.150^{* * *}(0.023)$ & $-0.321^{\text {*** }}(0.016)$ \\
\hline Countryside & $0.149^{* * *}$ & $(0.022)$ & $-0.165^{* * *}$ & $(0.023)$ & $0.129^{* * *}(0.019)$ & $-0.285^{* * *}(0.041)$ & $-0.344^{* * *}(0.020)$ \\
\hline General accessibility & $-0.040^{* * *}$ & $(0.005)$ & $0.105^{* * *}$ & $(0.006)$ & $-0.050^{* * *}(0.004)$ & $0.173^{* * *}(0.009)$ & a \\
\hline Comp. better accessibility by pub. transp. & $-0.071^{* * *}$ & $(0.011)$ & $0.025^{*}$ & $(0.011)$ & & & \\
\hline Comp. better job accessibility & $-0.574^{* * *}$ & $(0.056)$ & $0.850^{* * *}$ & $(0.059)$ & & & \\
\hline Log household income & $0.439^{* * *}$ & $(0.013)$ & $0.038^{* *}$ & $(0.013)$ & & & \\
\hline Car always available & & & & & $0.992^{* * *}(0.015)$ & $-0.704^{* * *}(0.024)$ & $-0.451^{* * * *}(0.016)$ \\
\hline Subscription to season ticket & & & & & $-0.550^{* * *}(0.016)$ & $1.777^{* * *}(0.025)$ & $-0.050^{* *} \quad(0.017)$ \\
\hline Constant & $-4.180^{* * *}$ & $(0.106)$ & $-0.737^{* * *}$ & $(0.107)$ & $-0.996^{* * *}(0.024)$ & $-2.440^{* * *}(0.041)$ & $0.525^{* * * *}(0.024)$ \\
\hline Dispersion parameter $\theta$ & & & & & $1.367^{* * *}(0.024)$ & $1.482^{* * *}(0.103)$ & $0.817^{\text {**** }}(0.016)$ \\
\hline Flexibility parameter $\varphi$ & & & & & $0.103^{* * *}(0.007)$ & $0.316^{* * *}(0.019)$ & $0.319^{* * *}(0.008)$ \\
\hline Observations & & 52476 & & 52476 & 52476 & 52476 & 52476 \\
\hline Log likelihood at convergence & & -29009 & & -27361 & -75641 & -25986 & -65418 \\
\hline Log likelihood constant only model & & -33614 & & -30042 & -81353 & -32361 & -66278 \\
\hline Pseudo $R^{2}$ & & 0.137 & & 0.089 & 0.070 & 0.190 & 0.013 \\
\hline
\end{tabular}

Table 6: Univariate estimation results.

in the city center. Living in the city center shows a greater likelihood of subscribing to a season ticket than living in the agglomeration and the countryside.

For each of the three count outcomes of the number of trips we find significant structural effects of the two mobility tools. The observed differences for the number of car trips and season ticket ownership in Table 3 are replicated by the model estimates in Table 7, except for the effects of season ticket on the number of non-motorized trips. Table 3 shows a slightly greater average of non-motorized trips for season tickets holder, but the effect in Table 7 is negative. This is anticipated because in Table 3 many other covariates are not considered, e.g., spatial typology. The number of car trips increases in the countryside and even more in the agglomeration. The number of public transport trips is highest in the city center and decreases in the agglomeration and even more so in the countryside. This pattern is also observed for the number of non-motorized trips. With increasing general accessibility, the number of car trips declines and the number of public transport trips increases. The effect of general accessibility on the number of non-motorized trips is insignificant.

In Table 8, we list the cross-equation parameters of all five outcomes. Except for the correlations between equations of season ticket ownership and number of non-motorized trips and between equations of the number of public transport trips and non-motorized trips, all correlations are significant. A negative correlation means that common unobserved factors affect both outcomes in opposite di- 


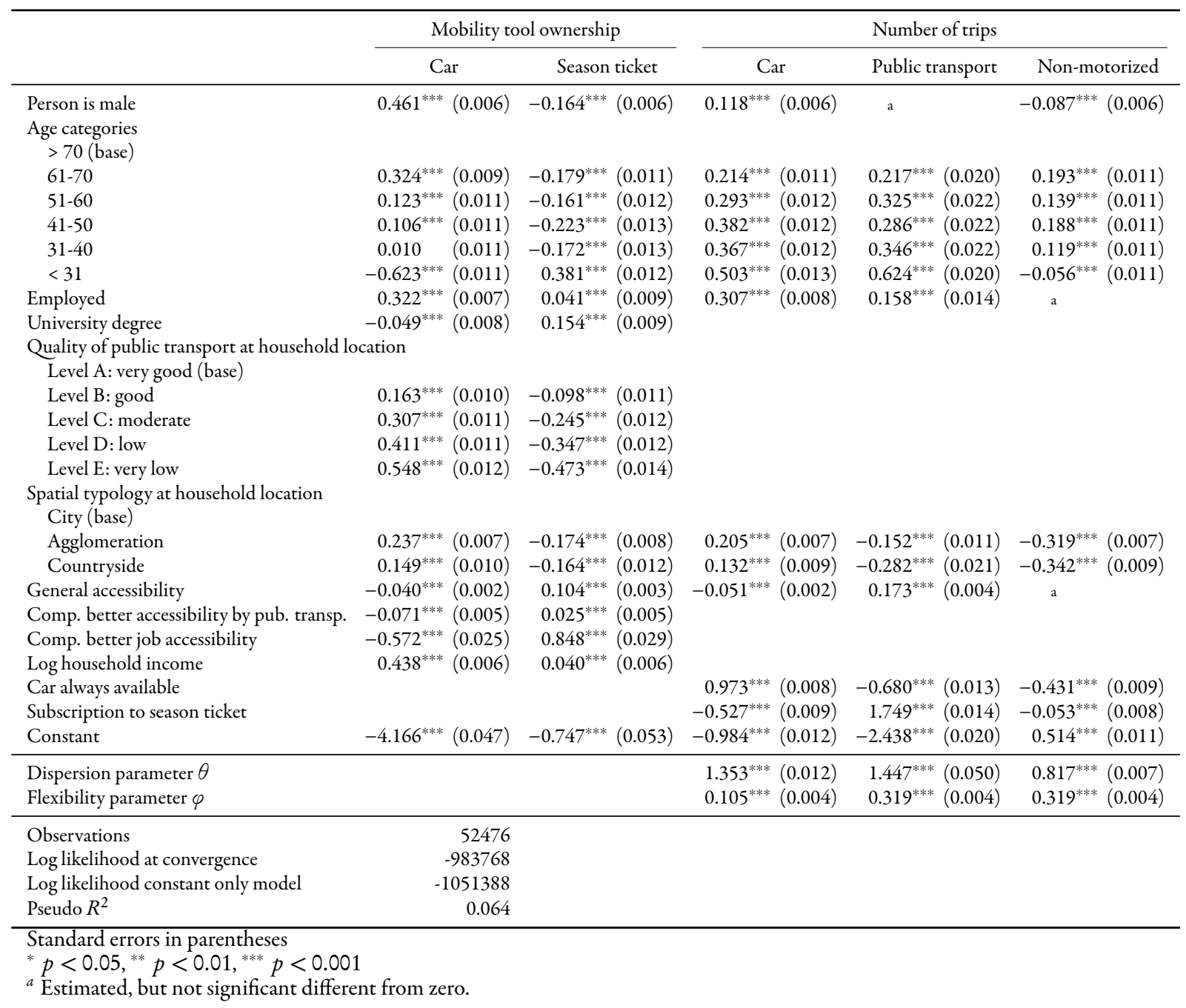

Table 7: Multivariate estimation results; estimates obtained using the MACML procedure

rections, e.g., the motivation for buying a season ticket can be contrary to having a car, while a positive correlation means that common unobserved factors affect both outcomes in the same direction. In case of an insignificant correlation, we find no common unobserved factors that affect both outcomes simultaneously. The negative correlation between car and season ticket ownership indicates that both mobility tools are substitutes. This finding is consistent with previous findings (Scott and Axhausen 2006). Correlation between number of car and public transport trips and between car and non-motorized trips is negative, indicating that these types of travel are substitutes.

The values of all significant correlations that represent the structural effects between mobility tools and number trips are less than 0.1 in magnitude. We find that the correlation between car ownership and car trips as well as season ticket ownership and public transport trips is negative.

We expect that, in both cases, the negative correlations might capture unobserved factors such as the impetus to use the mobility tool due to a large financial commitment. For positive correlations of structural effects, we assume they might describe a general factor of demanding mobility. To validate the negative correlations for the two structural effects, we estimate Poisson and linear regression models with endogenous mobility tool ownership and also find negative correlations. We conclude that joint modeling of outcomes is necessary, because most cross-equation correlations are significant. 


\begin{tabular}{|c|c|c|c|}
\hline \multicolumn{4}{|c|}{ Between the mobility tools } \\
\hline$\rho_{21}$ & Car and season ticket & $-0.489^{* * *}$ & $(0.007)$ \\
\hline \multicolumn{4}{|c|}{ Between mobility tools and the number of trips } \\
\hline$\rho_{31}$ & Car and car trips & $-0.022^{* *}$ & $(0.008)$ \\
\hline$\rho_{41}$ & Car and public transport trips & $0.036^{* * *}$ & $(0.010)$ \\
\hline$\rho_{51}$ & Car and non-motorized trips & $0.016^{* *}$ & $(0.006)$ \\
\hline$\rho_{32}$ & Season ticket and car trips & $0.028^{* * *}$ & $(0.008)$ \\
\hline$\rho_{42}$ & Season ticket and public transport trips & $-0.037^{* * *}$ & $(0.009)$ \\
\hline$\rho_{52}$ & Season ticket and non-motorized trips & -0.006 & $(0.008)$ \\
\hline \multicolumn{4}{|c|}{ Between the number of trips by } \\
\hline$\rho_{43}$ & Car and public transport & $-0.355^{* * *}$ & $(0.007)$ \\
\hline$\rho_{53}$ & Car and non-mot. modes & $-0.281^{* * *}$ & $(0.005)$ \\
\hline$\rho_{54}$ & Public transport and non-mot. modes & -0.013 & $(0.008)$ \\
\hline
\end{tabular}

Table 8: Estimates of the correlation between unobserved factors

We find with a likelihood-ratio test that the joint modeling approach improves the model significantly when compared to a model with the correlation matrix constraint to the identity matrix. Furthermore, we scrutinize the fit of the model by investigating the log likelihood for outliers (Ben Akiva and Lerman 1985). In the distribution we observe that $10 \%$ of the sample have a likelihood value several magnitudes away from the mean and median. We checked the extreme cases for consistency but did not experience conflicting outcomes. Further, we checked the sensitivity of the estimates when removing the most extreme outliers (less than $1 \%$ ) but did not find noticeable changes.

\section{Discussion}

We find that our results are consistent with previous findings, e.g., for the effects of the built environment (Ewing and Cervero 2010) and for Switzerland (Kowald et al. 2017; Simma and Axhausen 2001). However, we have to address certain methodological and data issues.

We decided to jointly model car and season ticket ownership, as well as the number of car trips, public transport and non-motorized modes for two main reasons. First, public transport is, in most regions of Switzerland, an attractive alternative to a car. Thus, we expect that the choice between both mobility tools is therefore made simultaneously. Second, owning a mobility tool is a large financial commitment to a mode and therefore a powerful predictor of using that mode. Therefore, the ownership of a mobility tool is endogenous. Based on these reasons, we decided to use Bhat's probit-based model for mixed types of outcomes; see Bhat et al. (2014) and Bhat (2015). However, we could also have applied other methodologies to compare our estimates. With interest only in mobility tool ownership, we could have modeled the decision making process with a multivariate probit (e.g., Yamamoto 2009), or a multinomial logit (e.g., Kowald et al. 2017; Vovsha and Petersen 2009). For the combination of jointly modeling ownership and travel activity, we could also have used copula based models (Spissu et al. 2009) or allowed for complementary and substitution patterns in multiple discrete continuous models (Bhat et al. 2015).

With the joint modeling approach, we also tried to capture not only the structural effects of ownership on use, but also the commitment or lock-in in the correlation matrix of the unobserved factors. However, in future research we have to consider these effects with special focus on the influence of residential location choice (self-selection), attitudes and spatial interactions (Bhat et al. 2016; Cao et al. 2009; Ewing and Cervero 2010; Mokhtarian and Cao 2008). In addition, we can extend this analysis to the influence of the workplace location for the employed. Further, we could consider instead of the number of trips the distance or time traveled by mode using Copula or multiple discrete-continuous extreme value models 
In this analysis, we used data from the Swiss transportation microcensus offering a one-day travel diary, but we could gain more insights into travel behavior by using a travel diary covering multiple days (e.g., Zimmermann et al. 2001). The model could also be expanded by using spatial information on each trip's start and end points, to estimate the effect of start and end locations on mode choice. In Switzerland, there are different options for buying a season ticket, i.e. local or nation-wide. In future research, we could distinguish between ticket types (see Becker et al. 2017; Loder and Axhausen 2016), but also validate the negative error correlation for the structural effects of car ownership and car trips, as well as season ticket and public transport trips using other data sets. Last, the introduced accessibility measure makes it difficult to predict how changes in accessibility by one mode affect all choices. When making predictions under these circumstances, researchers must change the input accessibility variable and transform it with component loadings.

\section{Conclusions}

In this paper, we present an approach to accommodate highly-correlated destination accessibility measures in travel behavior models by carrying out a principal component analysis on the accessibility measures and using the principal components in the modeling instead. We use the new accessibility variables as explanatory variables in modeling mobility tool ownership and number of car, public transport and non-motorized trips in Switzerland, employing a multivariate probit-based model for mixed types of outcomes (Bhat et al. 2014).

The model results show the expected signs that increasing general accessibility, comparatively better accessibility by public transport and comparatively better job accessibility reduces the probability of car ownership and increases the probability of season ticket ownership. Structural effects of mobility tool ownership on number of trips show the expected signs as well, e.g., car ownership increases the number of car trips. We observe that cars and season tickets are substitutes, as well as car and public transport trips. The effects of our other control variables in the model are consistent with previous research (Kowald et al. 2017; Scott and Axhausen 2006; Simma and Axhausen 2001). We conclude that jointly estimating mobility tool ownership and number of trips is necessary to avoid a bias in the estimated effects and to recover common unobserved factors affecting multiple outcomes.

The proposed approach for deriving accessibility measures through principal component analysis is of interest for all researchers in the field of built environment and modeling travel behavior. The model estimates are important for Swiss transport planners, because we present the first joint mobility tool ownership and travel activity model covering the private, public and non-motorized mode.

\section{Acknowledgments}

This work was supported by ETH Research Grant ETH-04 15-1. The authors thank the anonymous referees for the very helpful comments that contributed to this paper. The authors thank Karen Ettlin and Basil Schmid for their comments on this paper. 


\section{References}

Andrés, J. and G. Gélvez. 2014. Joint disaggregate modeling of car and motorcycle ownership: A case study of Bogotá, Colombia. Transportation Research Record: Journal of the Transportation Research Board, 2451:149-156. doi: 10.3141/2451-17.

Anowar, S., N. Eluru, and L. F. Miranda-Moreno. 2014. Alternative modeling approaches used for examining automobile ownership: A comprehensive review. Transport Reviews, 34(4):441-473. doi: 10.1080/01441647.2014.915440.

Becker, H., A. Loder, B. Schmid, and K. W. Axhausen. 2017. Modeling car-sharing membership as a mobility tool: A multivariate probit approach with latent variables. Travel Behaviour and Society, 8:26-36. doi: https://doi.org/10.1016/j.tbs.2017.04.006.

Ben Akiva, M. E. and S. R. Lerman. 1985. Discrete choice analysis: Theory and application to travel demand. MIT Press series in transportation studies. Cambridge, MA, US: MIT Press.

Bento, A., M. L. Cropper, A. M. Mobarak, and K. Vinha. 2005. The effects of urban spatial structure on travel demand in the United States. Review of Economics and Statistics, 87(3):466-478. doi: $10.1162 / 0034653054638292$.

Bhat, C. R. 2005. A multiple discrete-continuous extreme value model: Formulation and application to discretionary time-use decisions. Transportation Research Part B: Methodological, 39(8):679707. doi: $10.1016 /$ j.trb.2004.08.003.

Bhat, C. R. 2015. A new generalized heterogeneous data model (GHDM) to jointly model mixed types of dependent variables. Transportation Research Part B: Methodological, 79:50-77. doi: 10.1016/j.trb.2015.05.017.

Bhat, C. R., S. Astroza, R. Sidharthan, M. J. B. Alam, and W. H. Khushefati. 2014. A joint count-continuous model of travel behavior with selection based on a multinomial probit residential density choice model. Transportation Research Part B: Methodological, 68:31-51. doi: 10.1016/j.trb.2014.05.004.

Bhat, C. R., M. Castro, and A. Rawoof. 2015. Allowing for complementarity and rich substitution patterns in multiple discrete - continuous models. Transportation Research Part B: Methodological, 81:59-77. doi: 10.1016/j.trb.2015.08.009.

Bhat, C. R. and J. Y. Guo. 2007. A comprehensive analysis of built environment characteristics on household residential choice and auto ownership levels. Transportation Research Part B: Methodological, 41(5):506-526. doi: 10.1016/j.trb.2005.12.005.

Bhat, C. R., A. R. Pinjari, S. K. Dubey, and A. S. Hamdi. 2016. On accommodating spatial interactions in a Generalized Heterogeneous Data Model (GHDM) of mixed types of dependent variables. Transportation Research Part B: Methodological, 94:240-263. doi: 10.1016/j.trb.2016.09.002.

Bhat, C. R. and S. Sen. 2006. Household vehicle type holdings and usage: An application of the multiple discrete-continuous extreme value (MDCEV) model. Transportation Research Part B: Methodological, 40(1):35-53. doi: 10.1016/j.trb.2005.01.003.

Bhat, C. R. and R. Sidharthan. 2011. A simulation evaluation of the maximum approximate composite marginal likelihood (MACML) estimator for mixed multinomial probit models. Transportation Research Part B: Methodological, 45(7):940-953. doi: 10.1016/j.trb.2011.04.006.

Bhat, C. R., C. Varin, and N. Ferdous. 2010. A comparison of the maximum simulated likelihood and composite marginal likelihood estimation approaches in the context of the multivariate ordered response model. In Maximum simulated likelihood methods and applications, pp. 65-106. Elsevier. doi: 10.1108/S0731-9053(2010)0000026007.

Cao, X., P. L. Mokhtarian, and S. L. Handy. 2007. Do changes in neighborhood characteristics lead to changes in travel behavior? A structural equations modeling approach. Transportation, 34(5):535556. doi: $10.1007 / \mathrm{s} 11116-007-9132-x$.

Cao, X. J., P. L. Mokhtarian, and S. L. Handy. 2009. Examining the impacts of residential self-selection on travel behaviour: A focus on empirical findingss. Transport Reviews, 29(3):359-395. doi: 


\section{$10.1080 / 01441640802539195$.}

Cervero, R. and K. Kockelman. 1997. Travel demand and the 3Ds: Density, diversity, and design. Transportation Research Part D: Transport and Environment, 2(3):199-219. doi: 10.1016/S13619209(97)00009-6.

Crozet, Y., A. Mercier, and N. Ovtracht. 2012. Accessibility: a key indicator to assess the past and future of urban mobility. In Accessibility analysis and transport planning challenges for Europe and North America, pp. 263-279. Cheltenham, UK and Northampton, MA, USA: Edward Elgar Publishing. doi: 10.4337/9781781000106.00025.

Dargay, J., D. Gately, and M. Sommer. 2007. Vehicle ownership and income growth, worldwide: 19602030. The Energy Journal, 28(4):143-170.

Dargay, J. M. 2002. Determinants of car ownership in rural and urban areas: A pseudo-panel analysis. Transportation Research Part E: Logistics and Transportation Review, 38(5):351-366. doi: 10.1016/S1366-5545(01)00019-9.

de Jong, G., J. Fox, A. Daly, M. Pieters, and R. Smit. 2004. A comparison of car ownership models. Transport Reviews, 24(4):379-408. doi: 10.1080/0144164032000138733.

de Jong, G. C. and R. Kitamura. 2009. A review of household dynamic vehicle ownership models: Holdings models versus transactions models. Transportation, 36(6):733-743. doi: 10.1007/s11116-009-9243-7.

Eluru, N., A. R. Pinjari, R. M. Pendyala, and C. R. Bhat. 2010. An econometric multi-dimensional choice model of activity-travel behavior. Transportation Letters: The International Journal of Transportation Research, 2(4):217-230. doi: 10.3328/TL.2010.02.04.217-230.

Ewing, R. and R. Cervero. 2001. Travel and the built environment: A synthesis. Transportation Research Record: Journal of the Transportation Research Board, 1780:87-114.

Ewing, R. and R. Cervero. 2010. Travel and the Built Environment. Journal of the American Planning Association, 76(3):265-294.

Ewing, R. and R. Cervero. 2017. "Does compact development make people drive less?" The answer is yes. Journal of the American Planning Association, 83(1):19-25. doi: $10.1080 / 01944363.2016 .1245112$.

Geurs, K. T. and B. van Wee. 2004. Accessibility evaluation of land-use and transport strategies: review and research directions. Journal of Transport Geography, 12(2):127-140. doi: 10.1016/j.jtrangeo.2003.10.005.

Guo, J., C. Bhat, and R. Copperman. 2007. Effect of the built environment on motorized and nonmotorized trip making: Substitutive, complementary, or synergistic? Transportation Research Record: Journal of the Transportation Research Board, 2010:1-11. doi: 10.3141/2010-01.

Handy, S. L. and D. A. Niemeier. 1997. Measuring accessibility: An exploration of issues and alternatives. Environment and Planning A, 29(7):1175-1194. doi: 10.1068/a291175.

Hansen, W. G. 1959. How accessibility shapes land use. Journal of the American Institute of Planners, 25(2):73-76. doi: 10.1080/01944365908978307.

Houston, D., M. G. Boarnet, G. Ferguson, and S. Spears. 2014. Can compact rail transit corridors transform the automobile city? Planning for more sustainable travel in Los Angeles. Urban Studies, 52(5):938-959. doi: 10.1177/0042098014529344.

Jäggi, B., A. Erath, C. Dobler, and K. W. Axhausen. 2012. Modeling household fleet choice as a function of fuel price using a multiple discrete-continuous choice model. Transportation Research Record: Journal of the Transportation Research Board, 2302:174-183. doi: 10.3141/2302-19.

Jolliffe, I. T. 2002. Principal component analysis. New York: Springer.

Karlaftis, M. and J. Golias. 2002. Automobile ownership, households without automobiles, and urban traffic parameters: Are they related? Transportation Research Record: Journal of the Transportation Research Board, 1792:29-35. doi: 10.3141/1792-04.

Killer, V., R. Fuhrer, D. Guth, C. Holz-Rau, and K. W. Axhausen. 2013. Road accessibility of Germany and Switzerland 1970-2007. Arbeitsberichte Verkehrs-und Raumplanung, 936. 
Kowald, M., B. Kieser, N. Mathys, and A. Justen. 2017. Determinants of mobility resource ownership in Switzerland: Changes between 2000 and 2010. Transportation, 44(5):1043-1065. doi: 10.1007/s11116-016-9693-7.

Kuzmyak, J. R., C. Baber, and D. Savory. 2006. Use of walk opportunities index to quantify local accessibility. Transportation Research Record: Journal of the Transportation Research Board, 1977:145153. doi: 10.3141/1977-19.

Le Vine, S., M. Lee-Gosselin, A. Sivakumar, and J. Polak. 2013. A new concept of accessibility to personal activities: Development of theory and application to an empirical study of mobility resource holdings. Journal of Transport Geography, 31:1-10. doi: 10.1016/j.jtrangeo.2013.04.013.

Loder, A. and K. W. Axhausen. 2016. Patterns of mobility tool ownership. Arbeitsberichte Verkehrsund Raumplanung, 1170.

Madre, J.-L., K. W. Axhausen, and W. Brög. 2007. Immobility in travel diary surveys. Transportation, 34(1):107-128. doi: 10.1007/s11116-006-9105-5.

Metz, D. 2008. The myth of travel time saving. Transport Reviews, 28(3):321-336. doi: $10.1080 / 01441640701642348$.

Mokhtarian, P. L. and X. Cao. 2008. Examining the impacts of residential self-selection on travel behavior: A focus on methodologies. Transportation Research Part B: Methodological, 42(3):204228. doi: 10.1016/j.trb.2007.07.006.

Nolan, A. 2010. A dynamic analysis of household car ownership. Transportation Research Part A: Policy and Practice, 44(6):446-455. doi: 10.1016/j.tra.2010.03.018.

Paleti, R., C. Bhat, and R. Pendyala. 2013. Integrated model of residential location, work location, vehicle ownership, and commute tour characteristics. Transportation Research Record: Journal of the Transportation Research Board, 2382:162-172. doi: 10.3141/2382-18.

Potoglou, D. and P. S. Kanaroglou. 2008. Modelling car ownership in urban areas: a case study of Hamilton, Canada. Journal of Transport Geography, 16:42-54. doi: 10.1016/j.jtrangeo.2007.01.006.

Sarlas, G., R. Fuhrer, and K. W. Axhausen. 2015. Quantifying the agglomeration effects of Swiss public transport between 2000 and 2010. In Paper presented at the 15th Swiss Transport Research Conference, Ascona, April 2015.

Scott, D. M. and K. W. Axhausen. 2006. Household mobility tool ownership: modeling interactions between cars and season tickets. Transportation, 33(4):311-328. doi: 10.1007/s11116-005-03287.

Shen, Q. 2000. Spatial and social dimensions of commuting. Journal of the American Planning Association, 66(1):68-83. doi: 10.1080/01944360008976085.

Simma, A. and K. W. Axhausen. 2001. Structures of commitment in mode use: a comparison of Switzerland, Germany and Great Britain. Transport Policy, 8(4):279-288.

Spissu, E., A. R. Pinjari, R. M. Pendyala, and C. R. Bhat. 2009. A copula-based joint multinomial discrete-continuous model of vehicle type choice and miles of travel. Transportation, 36(4):403422. doi: 10.1007/s11116-009-9208-x.

StataCorp. 2015. Stata Statistical Software: Release 14.

Swiss Federal Office of Spatial Development (ARE). 2011. ÖV-Güteklassen-Berechnungsmethodik ARE. Neuchâtel: Swiss Federal Office of Spatial Development (ARE).

Swiss Federal Office of Spatial Development (ARE), Swiss Federal Office of Environment (BAFU), and Swiss Federal Statistical Office (BFS). 2011. Landschaftstypologie Schweiz. Neuchâtel: Swiss Federal Office of Spatial Development (ARE) and Swiss Federal Office of Environment (BAFU) and Swiss Federal Statistical Office (BFS).

Swiss Federal Office of Statistics (BFS) and Swiss Federal Office of Spatial Development (ARE). 2012. Mobilität in der Schweiz - Ergebnisse des Mikrozensus Mobilität und Verkehr 2010. Neuchâtel: Swiss Federal Office of Statistics (BFS) and Swiss Federal Office of Spatial Development (ARE). 
Tanner, R. and D. Bolduc. 2014. The Multiple Discrete-continuous Extreme Value Model (MDCEV) with Fixed Costs. Procedia - Social and Behavioral Sciences, 111:390-399. doi: 10.1016/j.sbspro.2014.01.072.

Vovsha, P. and E. Petersen. 2009. Model for Person and Household Mobility Attributes. Transportation Research Record: Journal of the Transportation Research Board, 2132:95-105. doi: Doi10.3141/2132-11.

Weis, C. and K. W. Axhausen. 2009. Induced travel demand: Evidence from a pseudo panel data based structural equations model. Research in Transportation Economics, 25(1):8-18. doi: 10.1016/j.retrec.2009.08.007.

Yamamoto, T. 2009. Comparative analysis of household car, motorcycle and bicycle ownership between Osaka metropolitan area, Japan and Kuala Lumpur, Malaysia. Transportation, 36(3):351366. doi: 10.1007/s11116-009-9196-x.

Zegras, C. 2010. The built environment and motor vehicle ownership and use: Evidence from Santiago de Chile. Urban Studies, 47(July):1793-1817. doi: 10.1177/0042098009356125.

Zimmermann, A., K. W. Axhausen, J. Beckmann, K. J. Beckmann, M. Düsterwald, E. Fraschini, T. Haupt, A. König, A. Kübel, G. Rindsfüser, R. Schlich, S. Schönfelder, A. Simma, and T. Wehmeier. 2001. Mobidrive: Dynamik und Routinen im Verkehrsverhalten: Pilotstude Rhythmik. Final report, PTV and IVT, ETH Zurich and Institut für Stadtbauwesen und Strassenverkehr (ISB), RWTH Aachen, Karlsruhe, Zurich and Aachen. 


\begin{tabular}{lcccc}
\hline & \multicolumn{4}{c}{ Means of transportation } \\
\cline { 2 - 5 } Headway & Rail junction & Rail & Tram, bus, ship & Cablecar \\
\hline$<5$ min & I & I & II & V \\
$5-10 \mathrm{~min}$ & I & II & III & V \\
$10-20 \mathrm{~min}$ & II & III & IV & V \\
$20-40 \mathrm{~min}$ & III & IV & V & V \\
$40-60 \mathrm{~min}$ & IV & V & V & V \\
\hline
\end{tabular}

Table 9: Public transport stop classification

\begin{tabular}{lcccc}
\hline & \multicolumn{4}{c}{$\begin{array}{c}\text { Distance in meters to the transport stop } \\
\text { from the household location }\end{array}$} \\
\cline { 2 - 5 } Stop Classification & $<300$ & $300-500$ & $501-750$ & $751-1000$ \\
\hline I & $\mathrm{A}$ & $\mathrm{A}$ & $\mathrm{B}$ & $\mathrm{C}$ \\
II & $\mathrm{A}$ & $\mathrm{B}$ & $\mathrm{C}$ & $\mathrm{D}$ \\
III & $\mathrm{B}$ & $\mathrm{C}$ & $\mathrm{D}$ & $\mathrm{E}$ \\
IV & $\mathrm{C}$ & $\mathrm{D}$ & $\mathrm{E}$ & $\mathrm{E}$ \\
V & $\mathrm{D}$ & $\mathrm{E}$ & $\mathrm{E}$ & $\mathrm{E}$ \\
\hline
\end{tabular}

Table 10: Classification of the level of access to public transport

\section{Appendix}

\section{Calculation of the local access to public transport measure}

The five level scale of the local access to public transport is obtained as follows. First, each public transport stop is characterized by means of transportation and headway on a five level scale from I to $\mathrm{V}$ according to Table 9. For multiple means of transportation at a stop, the lowest value is chosen. For the estimation of the local access, the above classification is paired with each household's distance to this stop according to Table 10. For each household, the best stop determines the level. All households located farther away than $1000 \mathrm{~m}$ from the next stop are classified in Level E. 